\title{
INTERVAL OSCILLATION THEOREMS FOR SECOND ORDER NONLINEAR PARTIAL DELAY DIFFERENTIAL EQUATIONS
}

\author{
Shuli Cui And Zhiting XU
}

Abstract. Using the integral averaging method and the generalized Riccati technique, we derive new interval oscillation criteria for second order nonlinear partial delay differential equations. These results are different from most known ones in the sense that they are based on information only on a sequence of subintervals of $[0, \infty)$, rather than on the whole $[0, \infty)$. Our results are of a high degree of generality and sharper than the existing results in literature.

Mathematics subject classification (2000): 34K11, 35B05, 34C55.

Keywords and phrases: oscillation, partial delay differential equations, interval criteria, integral averaging method, generalized Riccati technique.

\section{REFERENCES}

[1] D. D. Bainov, D. P. Mishev, Oscillation theory for neutral differential equations with delay, Adam Hilger, New York, 1991.

[2] B. T. CUI, W. N. LI, A necessary and sufficient condition for oscillation of parabolic equations with several delays, J. Comput. Appl. Math., 95 (1998), 153-156.

[3] B. T. CUI, Y. H. YU, S. Z. Lin, Oscillation of solutions of delay hyperbolic differential equations, Acta. Math. Appl. Sinica., 19 (1996), 80-88.

[4] B. T. CUI, Oscillation properties of the solutions of hyperbolic equations with deviating arguments, Demonstratio Math., 29 (1996), 61-68.

[5] B. S. LalLi, Y. H. YU, B. T. CUI, Oscillation of hyperbolic equations with functional arguments, App. Math. Comput., 53 (1993), 97-110.

[6] W. N. LI, Oscillation for solutions of partial differential equations with delays, Demonstratio. Math., 33 (2000), 319-332.

[7] I. V. KAMENEV, An integral criterion for oscillation of linear differential equations, Mat. Zametki., 23 (1978), 249-251.

[8] Q. KONG, Interval criteria for oscillation of second order linear ordinary differential equations, J. Math. Anal. Appl., 229 (1999), 258-270.

[9] E. Minchev, N. YoshidA, Oscillation of solutions of vector differential equations of hyperbolic type with functional arguments, J. Comput. Appl. Math., 151 (2003), 107-117.

[10] Y. SHOUKAKU, N. YOSHIDA, Oscillatory properties of the solutions of nonlinear parabolic equations with functional arguments, Indian J. Pure. Appl. Math., 34 (2003), 1469-1478.

[11] J. WANG, F. MENG, S. LiU, Integral average method for oscillation of second order partial differential equations with delays, Appl. Math. Comput., 187 (2007), 815-823.

[12] J. WANG, F. MENG, S. LiU, Interval oscillation criteria for second order partial differential equations with delays, J. Comput. Appl. Math., 212 (2008), 397-405.

[13] J. WU, Theory and applications of partial functional differential equations, Springer-Verlag, New York, 1996.

[14] Q. YE, Z. LI, Introduction to reaction-differential equations, Science Press, Beijing, 1990.

[15] N. Yoshida, Oscillation of nonlinear parabolic equations with function arguments, Hiroshima Math. J., 16 (1986), 305-314. 